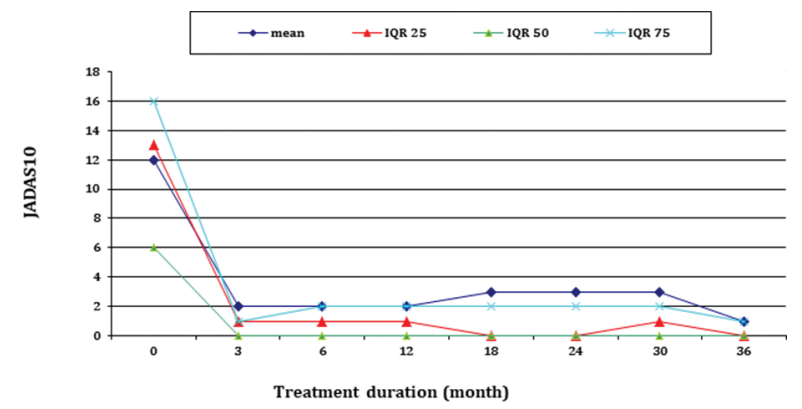

Acknowledgement: The authors acknowledge all contributors to BIKER, patients, parents and study staff

Disclosure of Interests: Gerd Horneff: None declared, Eggert Lilienthal: None declared, Ralf Trauzeddel: None declared, Toni Hospach Speakers bureau: Chugai, Roche, Novartis, Tilmann Kallinich Grant/research support from: Novartis, Speakers bureau: Sobi, Roche, Novartis, CLB, Frank Dressler Paid instructor for: Abbvie, Pfizer, Novartis, Michaela SailerHoeck: None declared, Gerd Ganser: None declared, Frank Weller-Heinemann: None declared, Georg Heubner: None declared, Andreas Urban: None declared, Michael Rühlmann: None declared, Christoph Rietschel: None declared, Markus Hufnagel: None declared, Wolfgang Emminger: None declared, Ariane Klein: None declared

DOI: 10.1136/annrheumdis-2019-eular.1429

\section{FRI0545 HEMODYNAMIC MEASUREMENTS AND ARTERIAL STIFFNESS IN PATIENTS WITH JUVENILE IDIOPATIC ARTHRITIS COMPARED TO CHILDREN WITHOUT JUVENILE IDIOPATIC ARTHRITIS}

Jorge E. Rubio Silveira ${ }^{1}$, C. Araceli Arellano Valdez ${ }^{1}$, Carlos Ramos Becerra ${ }^{2}$, Myriam Mendez Nuñez ${ }^{1}$, David Cardona Müller ${ }^{2}$, Oscar Mares Flores ${ }^{2}$, Priscila Vega García ${ }^{2}$, Fernando Grover Páez ${ }^{2}$, Alberto Tlacuilo Parra ${ }^{3} .{ }^{1}$ Instituto Mexicano del Seguro Social. Centro Médico Nacional de Occidente, Pediatric Rheumatology, Guadalajara, Mexico; ${ }^{2}$ Universidad de Guadalajara, Vascular Mechanics, Guadalajara, Mexico; ${ }^{3}$ Instituto Mexicano del Seguro Social. Centro Médico Nacional de Occidente, Research Chief, Guadalajara, Mexico

Background: Juvenile Idiopathic Arthritis (JIA) can cause long-term cardiovascular complications. There are non-invasive, validated, easy to perform methods for cardiovascular testing, such as: carotid intimal-media thickness (CIMT), and measurement of arterial rigidity through carotid distensibility, carotid-femoral pulse wave velocity (cfPWV) and the augmentation index (Alx).

Objectives: To compare the main hemodynamics measurements (cIMT, carotid distensibility, cfPWV and Alx) between JIA and non-JIA subjects. Methods: Analytical cross-sectional study in subjects 5 to 16 years of age. Two groups: patients with JIA according to the ILAR classification without any other condition vs healthy children. Measurements: somatometry, laboratory (glucose, creatinine, lipid profile), disease activity index (JADAS-27) and hemodinamic variables (cIMT, carotid distensibility, cfPWV and Alx).

Results: $63 \mathrm{JIA}$ subjects and 50 healthy controls were included, mean age $11.5 \pm 2.8$ vs $10.7 \pm 3.2$ years $(p=0.17)$ and $70 \%$ vs $54 \%$ females, respectively. Both groups were also similar $(p>0.05)$ for nutritional state, sedentary lifestyle, smoking habits and family history of cardiovascular risk. Table 1 show lipid profile of both groups. Subtypes of JIA were: RF positive polyarthritis (29\%), RF negative polyarthritis (29\%), oligoarthritis $(19 \%)$, enthesitis-related arthritis $(14 \%)$ and systemic arthritis $(9 \%)$. Mean time of disease evolution was $4 \pm 3$ años. There were no significant differences between groups in the main hemodinamic parameters (table 2). When comparing inactive vs active disease and active disease vs controls there were no differences either, we found a discrete trend to less carotid distensibility and higher cfPWV in patients with active disease compared to controls $[0.63 \pm 0.17 \mathrm{~mm}$ vs $0.66 \pm 0.15$ $\mathrm{mm}(p=0.94)$ and $6.12 \pm 2.88 \mathrm{~m} / \mathrm{s}$ vs $5.42 \pm 0.75 \mathrm{~m} / \mathrm{s}(p=0.33)$, respectively]. $59 \%$ of subjects with JIA were inactive according to JADAS-27. When considering time of disease evolution, children with 0-4 years vs children with $>4$ years and children with $>4$ years vs controls, we found differences in cIMT $[0.41 \pm 0.62 \mathrm{~mm}$ vs $0.44 \pm 0.50 \mathrm{~mm}(\mathrm{p}=$ $0.02)$ and $0.44 \pm 0.50 \mathrm{~mm}$ vs $0.40 \pm 0.70 \mathrm{~mm}(p=0.01)$, respectively].
Finally, cfPWV was higher in patients with $0-4$ years than in patients with $>4$ years of evolution $(p=0.01)$

TABLE 1. LIPID PROFILE

\begin{tabular}{lccc}
\hline LIPID & JIA & CONTROLS & $p_{\dagger}^{\dagger}$ \\
\hline Triglicerides & $94 \pm 56$ & $85 \pm 36$ & 0.22 \\
Total & $141 \pm$ & $152 \pm 26$ & 0.06 \\
cholesterol & 27 & & \\
HDL cholesterol & $45 \pm 12$ & $47 \pm 10$ & 0.36 \\
LDL cholesterol & $77 \pm 21$ & $87 \pm 22$ & 0.01 \\
VLDL & $18 \pm 11$ & $17 \pm 7$ & 0.52 \\
cholesterol & & &
\end{tabular}

†Mann-Whitney U test.

TABLE 2. HEMODINAMIC MEASUREMENTS

\begin{tabular}{lccc}
\hline MEASUREMENT & JIA & CONTROLS & $p_{\dagger}^{\dagger}$ \\
\hline clMT (mm) & $0.42 \pm$ & $0.40 \pm 0.70$ & 0.11 \\
& 0.59 & & \\
Carotid distensibility & $0.64 \pm$ & $0.66 \pm 0.15$ & 0.78 \\
(mm) & 0.16 & & \\
cfPWV $(\mathrm{m} / \mathrm{s})$ & $5.77 \pm 2$ & $5.42 \pm 0.75$ & 0.66 \\
Alx $(\%)$ & $69 \pm 15$ & $69 \pm 12$ & 0.64 \\
\hline
\end{tabular}

"Mann-Whitney U test.

Conclusion: We found a tendency to increased cardiovascular risk when the disease has more than 4 years of evolution, specially in patients with persistent active disease. Traditional and non-traditional cardiovascular risk factors add up in this population. We need longterm follow-up studies.

\section{REFERENCES:}

[1] Bohr AH, Fuhlbrigge RC, Pedersen FK, De Ferranti SD, Müller K. Premature subclinical atherosclerosis in children and young adults with juvenile idiopathic arthritis. A review considering preventing measures. Pediatr Rheumatol 2016; 14: 1-5.

[2] Sozeri B, Atikan BY, Ozdemir K, Mir S. Assessment of vascular function in systemic onset juvenile idiopathic arthritis. Clin Rheumatol 2016; 35: 16991703.

Disclosure of Interests: Jorge E. Rubio Silveira Grant/research support from: Grants from Roche and Abbvie for some national meetings, C. Araceli Arellano Valdez Grant/research support from: Grants from Roche for multiple national and international meetings., Speakers bureau: different conferences about Tocilizumab in meetings., Carlos Ramos Becerra: None declared, Myriam Mendez Nuñez: None declared, David Cardona Müller: None declared, Oscar Mares Flores: None declared, Priscila Vega García: None declared, Fernando Grover Páez: None declared, Alberto Tlacuilo Parra: None declared DOI: 10.1136/annrheumdis-2019-eular.4549

\section{\begin{tabular}{|l|l}
\hline FRI0546 TRAJECTORIES OF DISEASE ACTIVITY OVER THE \\
\hline
\end{tabular} FIRST THREE YEARS FOLLOWING JUVENILE IDIOPATHIC ARTHRITIS DIAGNOSIS}

Stephanie Shoop-Worrall ${ }^{1,2}$, Kimme Hyrich $^{2,3}$, Lucy Wedderburn ${ }^{4,5,6}$ Wendy Thomson ${ }^{3,7}$, Nophar Geifman ${ }^{1,8}{ }^{1}$ The University of Manchester, Centre for Health Informatics, Manchester, United Kingdom; ${ }^{2}$ The University of Manchester, Arthritis Research UK Centre for Epidemiology, Manchester, United Kingdom; ${ }^{3}$ Central Manchester University Hospitals NHS Foundation Trust, Manchester Academic Health Science Centre, NIHR Manchester Musculoskeletal BRC, Manchester, United Kingdom; ${ }^{4}$ GOS Institute of Child Health, University College London, Arthritis Research UK Centre for Adolescent Rheumatology, London, United Kingdom; ${ }^{5}$ Great Ormond Street Hospital NHS Foundation Trust, Paediatric Rheumatology, London, United Kingdom; ${ }^{6}$ NIHR Great Ormond Street Hospital Biomedical Research Centre, London, United Kingdom; ${ }^{7}$ The University of Manchester, Arthritis Research UK Centre for Genetics and Genomics, Manchester, United Kingdom; ${ }^{8}$ The University of Manchester, The Manchester Molecular Pathology Innovation Centre, Manchester, United Kingdom

Background: The advent of biological therapies and early aggressive treatment strategies have drastically changed prognoses for children and young people (CYP) with juvenile idiopathic arthritis (JIA). Clinical trials and observational research have demonstrated improvements in disease for the majority, but not all, CYP over time. It is not currently known what the patterns of disease activity are in CYP with JIA and how these cluster over time. 